\title{
MYD88 NP_002459.2:p.L265P
}

National Cancer Institute

\section{Source}

National Cancer Institute. MYD88 NP 002459.2:p.L265P. NCI Thesaurus. Code C128178.

A change in the amino acid residue at position 265 in the myeloid differentiation primary response protein MyD88 where leucine has been replaced by proline. 